\title{
Sujeito e Subjetividade: aspectos silenciosos e silenciados na constituição dos sentidos
}

\section{Subject and Subjectivity: silent and silenced aspects in the constitution of the senses}

\section{Sujeto y Subjetividad: aspectos silenciosos y silenciados en la constitución de los sentidos}

\section{Clarice Pimentel Paulon*}

Universidade de São Paulo - USP, Ribeirão Preto, São Paulo, Brasil

\section{Leda Verdiani Tfouni**}

Universidade de São Paulo - USP, Ribeirão Preto, São Paulo, Brasil

\section{J uliana Bartijotto***}

Universidade de São Paulo - USP, Ribeirão Preto, São Paulo, Brasil

\begin{abstract}
RESUMO
Este trabalho propõe investigar as noções de subjetividade e sujeito para compreender aspectos constituintes do sentido. Pela Análise do Discurso (AD), investiga-se a subjetividade através da relação entre inter e intradiscurso, posição-sujeito e entrelaçamentos das formações discursivas. Pela Psicanálise, retomamos a constituição do sujeito descrita por Lacan que se conjectura na máxima: "O significante é o que representa o sujeito para outro significante". Nessas perspectivas, pretendemos apresentar possíveis respostas para as questões: Onde se encontra o sujeito lacaniano e qual a sua relação com a subjetividade? Assim, utilizaremos a noção de silêncio enquanto operador lógico, como propõe Tfouni (1998). O silêncio é considerado como agente, ora limitador, ora limitado pela palavra; ora alienado, ora separado do sentido. Na constituição da subjetividade, ele permite a ilusão de coesão, demarcando, em determinada materialidade, uma posição-sujeito. Desse modo, observa-se que o silêncio age tanto via repetição quanto via atos falhos, possibilitando a emergência de um sentido singular àquela subjetividade. O silêncio na lógica significante permite que ele seja tomado como articulador do sentido que engaja a escuta analítica pela mobilização do interdito. Para elucidar esses aspectos teóricos ressaltaremos dois casos reconhecidos na literatura analítica: o caso Aimée e o Esquecimento de Nomes Próprios.
\end{abstract}

Palavras-chave: silêncio, ato falho, sujeito, discurso.

\section{ABSTRACT}

The aim of this article is to investigate the notions of subject and subjectivity in order to gasp constitutive aspects of meaning. In the Discourse Analysis, subjectivity is examined in its relationship with inter and intradiscourse, as 
well as in the interrelationship between discursive formations, a theoretical field which includes both the materiality of history and the equivocity of the language. In Psychoanalysis, we undertake the constitution of the subject as it is described by Lacan through the maxim "The signifier is what constitutes the subject to another signifier". The notion of silence will be used as a logical operator, not as a phenomenon. Silence is here considered an agent, sometimes limiting and sometimes being limited by the words. In the constitution of subjectivity, it is what permits the illusion of coherence and cohesion of identity, in order to mark a specific subject position. The inclusion of silence into the logic of signification permits it to be taken as the articulator of meaning, which involves analytical hearing through manipulation of the banned. In order to elucidate these aspects, we will take two classical cases of the psychoanalytical literature: Lacan's Aimée, and Freud's Proper Names Oblivion.

Keywords: subjectivity, subject, Freudian slip, discourse.

\section{RESUMEN}

Este trabajo propone investigar las nociones de subjetividad y sujeto, con el fin de comprender aspectos constituyentes del sentido. En el Análisis del Discurso (AD), la subjetividad es investigada por la relación entre inter e intradiscurso y entrelazamientos de las formaciones discursivas, campo teórico que incluye la materialidad histórica, y la equivocidad de la lengua. Por el psicoanálisis, retomamos la constitución del sujeto tal como descrita por Lacan, en la máxima "lo significante es lo que representa un sujeto para otro significante". Utilizaremos la noción de silencio, resaltándolo como operador lógico, como propone F.E.V. Tfouni, y no como fenómeno. El silencio es considerado como un agente a veces limitador y otras veces limitado por la palabra. En la constitución de la cadena significante, es el significado de la función fálica: lo que da límite y dirige la cadena. En la constitución de la subjetividad, es lo que permite la ilusión de cohesión y coherencia de identidad, con el fin de demarcar, en determinada materialidad, una posición-sujeto específica. La inserción del silencio en la lógica significante posibilita que sea tomado como articulador del sentido, lo que compromete la escucha analítica por la movilización de lo entredicho. Para dilucidar estos aspectos, tomaremos dos casos reconocidos en la literatura analítica: el caso Aimée, de Lacan, y El olvido de los nombres propios, de Freud.

Palabras-clave: subjetividade, sujeto, acto fallo, discurso.

Repara bem no que não digo. Paulo Leminski

\section{CENA 1}

Após uma viagem de trem, indo da Ragusa (Dalmácia) para uma estação na Herzegovina, Freud (1901/1987) decide relatar um acontecimento ocorrido com ele: o esquecimento do nome do pintor Signorelli. Esse lapso de memória teve tal importância para Freud, que o leva a escrever sobre isso diversas vezes, tanto num jornal para o qual colaborava (sendo o artigo publicado cinco dias após sua viagem), quanto em cartas para seu colega Fliess, e em textos mais 
formais, destinados a publicação em livro. Fazemos notar, neste momento, que os meios de divulgação eram muito diferentes, o que pressupunha também interlocutores heterogêneos. As coincidências e desencontros entre o relatado em cada uma dessas oportunidades será o ponto de partida para a reflexão apresentada aqui. Retomamos abaixo a descrição cronológica dos fatos, de acordo com Peneda (1991):

Faz agora em 1998 cem anos que Freud esqueceu o nome do célebre pintor italiano Luca Signorelli. Este lapso de memória ocorreu no início de Setembro de 1898, quando Freud viajava de carruagem acompanhado de um desconhecido (Freyhau, advogado berlinense) de Ragusa (Dubrovnick), na Dalmácia, para Cattaro (Kotor), na Bósnia-Herzegovina. A 22 de Setembro, depois de regressar a Viena, Freud escreve a Fliess, e comunica-Ihe o lapso de memória: "não conseguia descobrir o nome do célebre pintor que fez o Juízo Final em Orvieto, o maior que já vi até hoje". Na carta de 27 de Setembro, Freud conta que transformou "Signorelli num pequeno ensaio" e que o enviou ao editor Ziehen \& Wernicke. Este texto transformar-seá no primeiro ensaio "sobre o mecanismo psíquico do esquecimento (falta de memória) zum psychischen Mechanismus der Vergesslichkeit". O ensaio pré-psicanalítico de 1898, que estará na origem do 1o capítulo da Psicopatologia (1901), dá-nos indicações precisas não só sobre a natureza dos fenômenos que constituem o objecto da invenção freudiana (neste caso o lapso de memória), como também, e muito em especial, faculta-nos uma imagem do mecanismo psíquico e das suas causas. O texto de 1898 representa, portanto, um valoroso testemunho das intuições originárias que vieram dar origem à psicanálise (objecto e método), assim como nos deixa algumas pistas para o enigma daquele que a inventou.

Em linhas gerais, trata-se de uma conversa informal com outro viajante (ora apresentado como um conhecido, ora um desconhecido), e, quando Freud (1901/1987) comenta sobre o afresco: As quatro últimas coisas, esquece-se do nome do pintor (Signorelli), surgindo dois substitutivos: Botticelli e Boltraffio. A partir dessa experiência de esquecimento, Freud elabora um mecanismo para elucidar como ele havia se dado. Para tanto, constrói uma cadeia associativa da qual participam ideias anteriores, alguns incidentes recentes da sua própria vida, o conteúdo do afresco e o seu interlocutor na viagem. Desenvolve, a partir daí, um esquema para explicar o processo de apagamento/recalque do significante (o nome de Signorelli), bem como o efeito desse recalque: 0 esquecimento do nome Signorelli. Partindo da segmentação desse 
nome próprio, Freud descobre que os sentidos aparentemente apagados estavam presentes nos fragmentos da palavra.

\section{CENA 2}

Em 1932, Lacan começa a atender em um hospital psiquiátrico a paciente Marguerite Anzieu, a quem irá nomear de Aimée (Amada) em sua tese de doutorado. Lacan (1932/1987) começa a atendê-la após Marguerite ter tentado matar com uma faca uma famosa atriz de teatro, a quem acusava de ter planejado a morte de seu filho.

O que surpreendeu Lacan (1932/1987), no momento em que começou a atendê-la, era o fato de que Marguerite, de algum modo, já não delirava mais. Ao investigar tal acontecimento, o autor recuperou a seguinte história: a mãe de Marguerite/Aimée presenciara a morte de sua primeira filha, também de nome Marguerite, queimada na lareira de casa em frente à mãe que, paralisada, não conseguiu salvar a filha. Assim, Marguerite era a segunda de seu nome naquela família, nascendo sob o signo de um luto que talvez não tivesse sido realizado pela mãe. Dessa forma, o autor coloca em sua tese de doutorado a passagem ao ato ${ }^{1}$ enquanto "cura" da paranoia de Marguerite/ Aimée, passagem ao ato tal que não significava nada, além de um ato de proteção ao filho, silenciado em sua história.

A partir da perspectiva desses dois casos e seus relatos, podemos vislumbrar alguns pontos de aproximação e divergência quanto ao direcionamento que tomaram, e seus efeitos. Pela via da aproximação, observamos que ambos tratam de um ocultamento silencioso de sentidos de suma importância ao sujeito. Ambos os casos também "resolvem-se" (dissolvem-se) de forma semelhante: a partir de um Outro ${ }^{2}$ (apesar de este Outro ter inscrições diferentes nos dois). No entanto, o efeito do silenciamento desses sentidos foi distinto nos dois casos. Por que tomaram rumos diferentes? Enquanto em um caso ocorreu um ato-falho através do esquecimento do nome do pintor, no outro caso houve uma passagem ao ato, atentando contra a vida de uma atriz. Qual seria a diferença? Onde ela estaria? Para investigar tal questão, empreenderemos uma expedição aos conceitos de sentido, da lógica do significante, e das noções de subjetividade e de sujeito.

\section{A noção de subjetividade}

A Análise do Discurso de linha francesa (AD), inaugurada por Pêcheux nos anos 1980, na França, vai além da dicotomia língua/fala proposta por Saussure (1916/2006), pautando-se na noção de discurso 
(Pêcheux, 1988). Sua proposta preconiza um sujeito interpelado pela ideologia e pelo inconsciente, o que remete a uma não intencionalidade do sujeito falante, sendo este descentrado. Desse modo, não há transparência na língua, o que torna o sentido múltiplo, não atrelado a somente um significado.

A partir dessa perspectiva podemos entrever que a noção de subjetividade em $A D$ se distingue de outras já expostas por teóricos sobre esse tema. Ao considerar como "terreno principal" para análise a materialidade linguística, a $A D$ não considera a existência de um "interno e externo". Semelhante à banda de Moebius - uma das primeiras figuras topológicas conjeturadas por Lacan (1962-63/2005) - o sujeito na Análise do Discurso é isento de interioridade e profundidade, não sendo equivalente nem ao sujeito gramatical, nem ao sujeito empírico da Sociologia. Assim, através dos dispositivos teóricos da AD, é possível entrever uma subjetividade da/na língua. Subjetividade essa que remete a uma posição, tanto diante do desejo, quanto diante da ideologia.

Para formalizar o conceito de posição-sujeito em AD, Pêcheux (1988) desenvolve dois conceitos que designa por "esquecimentos" ou "ilusões", ambos pautados na 1 a tópica freudiana ${ }^{3}$. O esquecimento no 1 é da ordem inconsciente, e produz no sujeito a ilusão de ser a origem de seu dizer. Trata-se do esquecimento ideológico, que produz a ilusão do único sentido possível. O esquecimento no 2 é da ordem pré-consciente, e é através dele que podemos formular e reformular o que dizemos pela escolha de palavras e da formação de enunciados. O autor coloca em relação aos dois esquecimentos que se trata do "acobertamento da causa do sujeito no próprio interior de seu efeito, ou seja, o sujeito se constitui pelo esquecimento que o determina" (Pêcheux, 1988, p. 150).

Nessa perspectiva, podemos observar que o sujeito é interpelado pelos esquecimentos e é através do funcionamento destes pela linguagem que ele se constitui. $O$ sujeito permanece então, na $A D$ como um lugar vazio a ser vislumbrado através das posições que ocupa, denominadas por Pêcheux (1988) posições-sujeito ${ }^{4}$.

O sentido, portanto, em $A D$, passa a ser compreendido em relação às posições-sujeito. Elas remetem a determinadas formações ideológicas que estabelecem relações imaginárias entre o eu e o (O)outro. No entanto, o sentido modifica-se constantemente. Como enuncia Pêcheux (2008) “... todo enunciado é intrinsicamente suscetível de tornar-se outro, diferente de si mesmo, se deslocar discursivamente de seu sentido para derivar para outro" (p. 53), afirmativa essa que pode ser entendida como uma proposição da autonomia do simbólico: o fato da inexistência de algo fora da linguagem. O referente do sentido é sempre outro sentido. Harari (2001), interpretando Frege (2009), faz o seguinte comentário em relação ao referente: 
“...à mesma estrela, chamada Vênus, se diz tanto estrela da manhã como estrela vespertina, de acordo com o momento de cada jornada. Assim, se tem distintos sentidos, possui a mesma significação. Portanto, significação quer dizer denotação, pois é o "mesmo objeto" chamado de outra maneira. Claro: se fossem unificados - utopicamente - poder-se-ia "chegar" à constituição da linguagem perfeita." (p. 98)

Se os sentidos pudessem ser unificados, como coloca Harari (2001), ou seja, se houvesse uma biunivocidade de sentido entre o objeto e seu referente, teríamos uma relação constante e indissociável entre significante e significado e, dessa forma, poderia haver uma literalidade na língua. No entanto, como o sentido escapa e pode deslizar para outras regiões semânticas, essa possibilidade deixa de aplicar-se às línguas naturais.

Além dos aspectos acima citados, o sentido em AD é constituído a partir de outros dois conceitos: 0 interdiscurso e o intradiscurso ${ }^{5}$ (Courtine, 1999). O interdiscurso diz respeito à materialidade histórica, à construção do sentido, se relacionando à memória discursiva. Ele é a região do já-dito, dos enunciados. O intradiscurso refere- se à enunciação, momento este onde o sentido é atualizado, trazendo à cena enunciativa parte da memória discursiva contida naquele sentido.

Desse modo, vislumbra-se que a cena enunciativa é composta por um dito e por um não-dito. Há aí um aspecto importante da constituição do dizer: o sentido é constituído também por aquilo que se faz calar e que, no entanto, permanece de algum modo na cena enunciativa. Trata-se aí da máxima da AD: "Dizer x, para não dizer y" (Pêcheux, 2008) podendo y, no entanto, ser deslocado, reaparecendo sob outras formas.

Fazemos notar, neste ponto, através dos mecanismos de interpretação na $A D$, aspectos relacionados ao registro do I maginário em Lacan (1975-76/2007). A relação entre locutores, a discursividade - pautada no inter e no intradiscurso - os aspectos ideológicos, e as posições-sujeito são conceitos que possibilitam ao analista interpretar a posição subjetiva, o local onde aquela formação discursiva se inscreve.

\section{A Psicanálise e o conceito de sujeito}

Gaufey (2010), realizando uma arqueologia do conceito lacaniano de sujeito, percorre os "rastros" que o autor deixou até chegar à fórmula: " um significante é aquilo que representa um sujeito para outro significante" (Lacan, 1964-65/2008, p. 194). 
Segundo aquele autor, o conceito de sujeito em Lacan vem para elucidar aos analistas a não reificação do inconsciente: afinal, enquanto estruturado como uma linguagem, o inconsciente não pode ter uma essência, nem ser considerado substância.

Desse modo, o autor inicia seu percurso para a conceituação de sujeito: passando pelo sujeito mentiroso (que ele contrapõe ao sujeito do 'cogito' cartesiano) e retomando depois o significante saussuriano para reformulá-lo através do quadrado lógico de Pierce, ele desenvolve a noção de traço unário, uma construção que permite que o sujeito possa ocupar o lugar do vazio e ser isento de reflexividade, marcado por uma ausência. Todos esses conceitos colocam-se sincronicamente na máxima lacaniana acima citada, estabelecida a posteriori: "Um significante é o que representa um sujeito para outro significante" (Lacan, 1964-65/2008, p. 194).

A primeira conceituação colocada por Lacan, a de sujeito mentiroso, traz à tona a noção de intersubjetividade. Propõe Lacan:

Dito isto, é preciso não omitir nossa suposição básica, a dos analistas: nós cremos que há outro sujeito além de nós, que há relações autenticamente intersubjetivas. Não teríamos motivo algum para pensá-lo se não tivéssemos o testemunho daquilo que caracteriza a intersubjetividade: que o sujeito pode mentirnos. É a prova decisiva. (Lacan citado por Gaufey, 2010, p. 15 [tradução nossa]).

Podemos, a partir dessa afirmativa de Lacan, observar que a noção de intersubjetividade proposta pelo autor está baseada no equívoco, na possibilidade de falha da linguagem. Isso acontece porque o Outro é, ao mesmo tempo, tesouro de significantes e barrado, pois não existe um único significante que represente o sujeito, sendo a nomeação "completa" do âmbito do impossível.

Além disso, essa perspectiva traz a noção de dialética: "nós cremos que há um sujeito além de nós"; ou seja, um outro. O sujeito que Lacan começa então a construir é um "termo relativo" (Gaufey, 2010, p. 16), nunca só. A coagulação imaginária que surge do encontro do sujeito com o Outro não é nada mais que o sentido, ao qual o sujeito irá alienar-se, calcando um eu, uma subjetividade, e desse modo, evanescendo-se (Pêcheux, 1988).

Fica aí exposto que a noção de subjetividade tem, então, a ver com uma supremacia de um eu, uma identificação, e não com o conceito de sujeito colocado por Lacan. O eu sutura um lugar vazio na cena enunciativa, lugar esse também dividido. O sujeito irá ocupar o lugar de corte na cadeia, de ser entre significantes. O sujeito é o próprio intervalo entre um significante primeiro e um segundo. No entanto, esse eu está vinculado ao sujeito, é enunciado por ele, no sentido de 
que o sujeito só pode surgir e "encobrir-se" na cadeia significante através da cena enunciativa.

O sujeito é associado a um significante, mas não totalmente recoberto por ele. É essa impossibilidade de fazer 'um' que permite a captação de uma singularidade, de aspectos subjetivos associados àquele sujeito falante. $\mathrm{O}$ que permite, na escuta analítica, vislumbrar esse sujeito, diz respeito à materialidade linguística, principalmente à sintaxe. Esse entretecido construído entre voz ativa (eu falo) e passiva (eu sou falado/o Outro fala em meu lugar) é onde pode ocorrer o aparecimento do sujeito, mostrando-Ihe a barra, e fazendo cair o objeto enquanto resto. Essa operação introduz um sujeito para além da ação, ou seja, aquele sujeito normalmente vinculado a um eu começa a despregar-se dele ${ }^{6}$.

Nesta perspectiva, assim como para a AD, a Psicanálise aponta para um descompasso entre enunciado e enunciação. O que é dito jamais pode ser dito totalmente, sendo a significação sempre incompleta.

Para que seja possível uma ordenação do processo de significação advinda da cadeia significante, sem a supremacia de um eu-pleno de sentido, Lacan (1962-63/2005, 1964-65/ 2008) explicita o conceito de função fálica, que tornará possível a significação, já que ordena a cadeia significante sem, no entanto, inscrever-se nela. Assim, o falo pode ser considerado como representante da falta. É ela que irá preconizar e permitir o deslizamento na cadeia significante, possibilitando a multiplicidade interpretativa.

Tal função entra no aporte teórico lacaniano através de dois vieses: ela dessubstantiviza o falo, colocando-o como predicado de uma função. Além disso, colocá-lo como associado a uma função é colocálo em um lugar vazio, que apenas é imbuído da movimentação na cadeia significante. Nesse sentido, ela passa a ser signo de que há sujeito, retomando a perspectiva de que só há sujeito na/em relação à linguagem.

Os cortes produzidos pela função fálica são essenciais para o desenrolar do sentido, já que é necessária uma descontinuidade para a continuidade e compreensão do enunciado. Nessa perspectiva, o silêncio seria constituinte da linguagem: estando a fala em relação dialética com o silêncio, este seria o impossível, índice que denota a divisão do sujeito e, ao mesmo tempo a ilusão de estabilidade do sentido.

Assim, o dito entre sujeitos, a intersubjetividade, como coloca Lacan, é aquilo que permite observar o sujeito do inconsciente, efeito entre significantes. Neste fragmento Lacan (1957/1998a) propõe:

Trata-se aqui daquele ser que só aparece no lampejo do instante do vazio do verbo ser, e eu disse que ele formula sua questão ao sujeito. Que significa isso? Ele não a coloca diante do sujeito, pois o sujeito não pode vir para o lugar onde ele a 
coloca, mas coloca-a no lugar do sujeito, ou seja, nesse lugar, ele coloca a questão com o sujeito, tal como se enuncia um problema com uma caneta e como o homem de Aristóteles pensava com sua alma. (p. 524)

Lacan (1957/1998a) mostra a relação entre sujeito e eu, sendo o eu (a 'alma' de Aristóteles) um predicado ao sujeito e a cadeia significante. É a partir do eu que o sujeito "intervém", ou seja, ele é um efeito na cadeia significante entrevisto a partir do momento em que o eu a enuncia, dando vistas assim, à suposta intencionalidade do sujeito do inconsciente.

\section{Discussão}

Retomando os referenciais teóricos da $A D$ e da Psicanálise, constatamos que é possível vislumbrar pontos de aproximação e de afastamento entre ambos na análise dos dois casos citados ( $O$ esquecimento de Freud e o caso Aimée de Lacan). Tanto em AD quanto na Psicanálise há uma preocupação com a constituição do sujeito pela linguagem, sendo esta linguagem não transparente, pautada no equívoco. Vemos também que ambas as teorias focalizam a noção de subjetividade e sentido.

No caso do esquecimento de Signorelli descrito por Freud, podemos detectar as posições-sujeito assumidas pelo autor nas diversas narrativas sobre o caso. Essas posições, como dito anteriormente, são pautadas na relação imaginária com a linguagem e na suposição de determinado interlocutor, como será discutido a seguir.

A análise indica que Freud silencia alguns aspectos do acontecimento quando se dirige a leitores virtuais como, por exemplo, a familiaridade com o companheiro de viagem; no entanto, ele não omitiu essa informação na carta à Fliess. Freud posiciona seu interlocutor no artigo e no capítulo do livro através das descrições: "companheiro de viagem" (Freud, 1898/ 1987, p. 276) e "um estranho" (Freud, 1901/1987, p. 21). Já, para Fliess, ele o nomeia: "Um advogado de Berlim (Freyhau) com quem comecei a conversar de fotografias..." (Freud citado por Masson, 1986, p. 328).

Há aí a assunção de duas formações discursivas antagônicas pelo sujeito Freud: uma, pautada no discurso científico, no intuito de formalizar a psicanálise; e outra baseada em uma relação de confiança e intimidade com o interlocutor, Fliess (seu Outrointerlocutor).

A primeira formação discursiva, alocada no discurso científico, é utilizada intencionalmente por Freud, a fim de caracterizar a psicanálise dentro de um paradigma científico dominante, o que exigiu do autor coesão e coerência textuais, para que fosse possível 
criar a ilusão de transparência do sentido característica desse discurso. Além disso, a nomeação por Freud de seu interlocutor no artigo redigido ao jornal ou no capitulo de Psicopatologia da Vida Cotidiana, colocaria em evidência traços de subjetividade de Freud, o que não é contemplado pelo discurso científico, que pretende isentarse desses aspectos, buscando antes uma objetividade absoluta. Residiria aí a explicação para o uso de 'estranho' e 'companheiro de viagem' no capítulo do livro e no artigo.

Na carta a Fliess, pode-se reconhecer, pela nomeação do interlocutor de viagem - 'Um advogado de Berlim (Freyhau)' -, que há traços de subjetividade ali, indicadores da relação familiar de Freud com Fliess. A nomeação de seu interlocutor no trem dá um estilo coloquial, quase confessional à carta, derivado da familiaridade entre ambos. Essa coloquialidade é uma das marcas da oralidade na escrita, e pressupõe uma posição subjetiva distinta. Tfouni, Pereira, Assolini, Sarti e Adorni (2008) argumentam sobre essa relação denominando-a de “... interpenetração dos discursos orais e escritos (...) que instalam lugares discursivos diferentes e determinam também relações diferentes entre sujeito e sentido" (p. 104). Essa interpenetração possibilita ao autor, através do discurso escrito, criar um efeito de informalidade, inscrevendo, no suporte gráfico da letra, aspectos subjetivos singulares do sujeito.

Pode-se concluir, nesse sentido, que a nomeação de seu interlocutor na publicação do caso é recalcada por Freud, ou seja, parte de um planejamento na condução do texto pautado por traços ideológicos determinados pela filiação ao discurso científico, o que é entrevisto na relação imaginária de Freud com seus interlocutores virtuais.

É importante também, neste caso, focar nos aspectos ideológicos constituintes do sentido na fabricação de Signorelli. É porque a ideologia dominante faz silenciar alguns sentidos, que eles aparecem deslocados. A questão da sexualidade, por exemplo, abordada pelo autor, era algo extremamente reprimido na época, o que promove modos de subjetivação distintos e um acesso outro ao sentido. Por isso Freud silencia após ter pensamentos sobre a sexualidade dos turcos, fato que é seguido pelo esquecimento do nome de Signorelli.

Assim, observamos que o silêncio age como limitador de sentidos específicos, demarcados pela ideologia dominante e pelas relações imaginárias que capturam o sujeito. Desse modo, o silêncio sai do âmbito do fenômeno para colocar-se como operador de uma lógica discursiva, calcada na incompletude da linguagem.

A presença de um lapso na fala do sujeito (o esquecimento do nome) é signo de haver sujeito do inconsciente, que está representado na passagem de um significante a outro significante. Como o sujeito está sempre em relação ao significante, ocupando o vazio, ele não se dá por uma ontologia. Pode-se inferir, nesse momento, que o sujeito (de Freud) é relacionado sincronicamente a Signorelli, já que é nesse 
lugar na cadeia que surgirá um buraco, indiciado pelo esquecimento e associado ao desejo. Um sentido que sempre remete a outro e mais outro que se inscreve no mesmo campo (o da linguagem), sendo que se referem a diversos objetos. Essa singularidade do sujeito, captada através da escuta significante, está em articulação com a fantasia - o modo de subjetivação que o sujeito encontra para barrar um encontro "direto" com o Real.

No caso Aimée, no entanto, a saída encontrada pelo sujeito em relação a um impasse subjetivo é outra: não a de um lapso na linguagem, mas sim de uma passagem ao ato. Isto pode ser explicado pelas estruturas clínicas lacanianas. Até onde se sabe, a hipótese diagnóstica de Aimée é a de psicose, estrutura depois conceituada por Lacan (1975-76/2007) como retorno do significante no registro do Real, o que causa um efeito distinto do efeito causado na neurose, onde ele retorna no simbólico, como acontece com Freud (no caso da psicose, aquilo que é da ordem do Imaginário aparece como da ordem do Real).

Isso não significa que não há, na psicose, uma relação com a linguagem. Apenas quer dizer que a relação com os significantes é distinta. É como ter uma outra referência ao sentido, sendo que esse escapa à inscrição no simbólico. Nem por isso, ele deixa de ser considerado linguagem. Na psicose não há a referência fálica, um ponto de basta na cadeia de significantes que possibilita uma amarração, como na neurose.

Parte-se, portanto, do mesmo silenciamento em Aimée e em Freud. Foi devido a um silenciamento na história de cada um que foi possível esse efeito na cadeia significante, seja ele lapso, seja ele passagem ao ato. Os entrelaçamentos que ocorreram como efeito desse silenciamento foram diversos; no entanto, a "cura" de ambos partiu do mesmo princípio: a intervenção de um Outro, seja como interlocutor, no caso de Freud (1901/1987), seja como "secretário" 7 , no caso de Aimée. Ou seja, nos dois casos o Outro se presentifica, mas no caso de Freud o Outro é barrado o que possibilita a emergência de um sujeito dividido e uma amarração da cadeia de significantes, enquanto no caso Aimée o Outro não é barrado, tornando a aparição do sujeito e a amarração de significantes impossíveis, o que é possível para ela é a passagem ao ato. Nessa perspectiva, a posição sujeito assumida por ambos pode ser associada ao seu sintoma: o retorno daquilo que foi silenciado e, no entanto, não cessa de não se inscrever. 


\section{Referências}

Costa, G. (2010). Posição-sujeito. In Glossário de termos - Análise do Discurso. Recuperado de <http://www.discurso.ufrgs.br/glossario.html\#C >

Courtine, J. J. (1999). O Chapéu de Clémentis. In Ferreira, M. C. L. e Indursky, F. (Orgs). Múltiplos territórios da Análise do Discurso (pp. 5-18) Porto Alegre, RS: Sagra Luzzatto.

Frege, G. (2009) Lógica e Filosofia da Linguagem. São Paulo: EDUSP.

Freud, S. (1987). Sobre o mecanismo psíquico do esquecimento. In Freud, S. (Vol. 2). Estudos sobre a histeria (pp. 275-280). São Paulo, SP: Imago. (Original publicado em 1898).

Freud, S. (1987). O esquecimento de nomes próprios. In Freud, S. (Vol. 6). Psicopatologia da Vida Cotidiana (pp. 19-24). São Paulo, SP: Imago, 19-24. (Original publicado em 1901).

Gaufey, G. (2010). El sujeto según Lacan. Buenos Aires, Argentina: El Cuenco de Plata.

Harari, R. (2001). O que acontece no ato analítico? - A experiência da psicanálise. Rio de Janeiro, RJ: Companhia de Freud.

Lacan, J. (1987). Da psicose paranoica e suas relações com a personalidade. Rio de Janeiro, RJ: Forense Universitária. (Original publicado em 1932).

Lacan, J. (1998a). A instância da letra no inconsciente ou a razão desde Freud. In Lacan, J. Escritos (pp. 496-533). Rio de Janeiro, RJ: Zahar. (Original publicado em 1957).

Lacan, J. (1998b). Subversão do sujeito e dialética do desejo no inconsciente freudiano. In: Lacan, J. Escritos (pp. 807-842). Rio de Janeiro, RJ : Zahar. (Original publicado em 1957).

Lacan, J. (2005). O seminário 10: A angústia. Rio de Janeiro, RJ: Zahar. (Original publicado em 1962-63).

Lacan, J. (2007). O seminário 23: Sinthoma. Rio de Janeiro, RJ: Zahar. (Original publicado em 1975-76).

Lacan, J. (2008). O seminário 11 . Os quatros conceitos fundamentais da psicanálise ( $2 a$ ed.). Rio de Janeiro, RJ: Zahar. (Original publicado em 1964-65).

Masson, J. M. (1986). Correspondência Completa de Sigmund Freud e Wilhelm Fliess 1887-1904. São Paulo, SP: Imago.

Pêcheux, M. (1988). Semântica e discurso - Uma crítica à afirmação do óbvio. (Orlandi, E. P. Trad). Campinas, SP: UNICAMP.

Pêcheux, M. (2008). O discurso: estrutura ou acontecimento (5a ed.). (Orlandi, E. P. Trad). Campinas, SP: UNICAMP.

Peneda, J. (1991). Sobre o mecanismo psíquico do esquecimento. In Peneda, J. Esquecimento e fantasma. Lisboa: Portugal: Assírio \& Alvim. Recuperado em 03 de abril de 2015 de $<$ http://areas. fba.ul.pt/jpeneda/Condensado\% 20Signorelli.htm $>$ 
Saussure, F. (2006). Curso de Linguística Geral (2a ed.). São Paulo, SP: Cultrix. (Original publicado em 1916).

Tfouni, F. V. (1998). O interdito como fundador do discurso (Dissertação de Mestrado), Instituto de Estudos da Linguagem, Universidade Estadual de Campinas (UNICAMP), Campinas, Brasil.

Tfouni, L. V., Pereira, A. D., Assolini, F. E. P., Sarti, M. \& Adorni, A. (2008). O caráter terapêutico da escrita: práticas de letramento em um hospital psiquiátrico. Paidéia, 18(39), 101-110. doi 10.1590/S0103-863X2008000100010.

\author{
Endereço para correspondência \\ Leda Verdiani Tfouni \\ Universidade de São Paulo - USP \\ Faculdade de Filosofia, Ciências e Letras de Ribeirão Preto \\ Av. Bandeirantes 3900, CEP 14040-900, Ribeirão Preto - SP, Brasil \\ Endereço eletrônico: Ivtfouni@usp.br \\ Clarice Pimentel Paulon \\ Universidade de São Paulo - USP \\ Instituto de Psicologia (IP-USP) \\ Av. Professor Mello Moraes, 1721, CEP 05508-030, São Paulo - SP, Brasil \\ Endereço eletrônico: cla_paulon@yahoo.com.br \\ J uliana Bartijotto \\ Universidade de São Paulo - USP \\ Faculdade de Filosofia, Ciências e Letras de Ribeirão Preto \\ Av. Bandeirantes 3900, CEP 14040-900, Ribeirão Preto - SP, Brasil \\ Endereço eletrônico: jubartijotto@gmail.com
}

Recebido em: 09/01/2016

Aceito em: 08/08/2017

\footnotetext{
Notas

* Mestre em Psicologia pelo Programa de Pós-Graduação em Psicologia da Universidade de São Paulo, Ribeirão Preto.

** Professora Titular do departamento de Psicologia da Universidade de São Paulo, Ribeirão Preto.

*** Mestre em Psicologia pelo Programa de Pós-Graduação em Psicologia da Universidade de São Paulo, Ribeirão Preto.

${ }^{1}$ A passagem ao ato para Lacan (1962-63/ 2005) é o momento eletivo em que o sujeito se apaga e se coloca no lugar de objeto, rejeitando a função do Outro (dimensão simbólica), pois não se trata de uma demanda endereçada a ele; tratase de um ato sem sentido prévio, mas que possui uma organização significante. $O$ sujeito se identifica de forma total com o objeto a (lugar de resto/dejeto) na tentativa de evitar a angústia.

2 Para Lacan (1957/1998b), o grande Outro (escrito com letra maiúscula) é a cadeia de significantes - dimensão simbólica - inscrita no inconsciente, cujo funcionamento é análogo ao da linguagem; é um campo aonde se manifesta a fala, por isso, a afirmação "o inconsciente é o discurso do Outro". O pequeno outro (com minúscula) é o semelhante, isto é, a imagem especular do sujeito inscrito na dimensão imaginária. Na psicose existe uma confusão entre outro e Outro e na neurose esses dois lugares são demarcados.
} 
${ }^{3}$ A primeira tópica freudiana sobre o aparelho psíquico é aquela que o divide em consciente, pré-consciente e inconsciente.

${ }^{4}$ Resultado da relação que se estabelece entre o sujeito do discurso e a formasujeito de uma dada formação discursiva. Uma posição-sujeito não é uma realidade física, mas um objeto imaginário, representando no processo discursivo os lugares ocupados pelos sujeitos na estrutura de uma formação social. Deste modo, não há um sujeito único, mas diversas posições-sujeito, as quais estão relacionadas com determinadas formações discursivas e ideológicas. (Recuperado de <http://www.discurso.ufrgs. br/glossario.html\#C>).

${ }^{5}$ Depois abarcados por Pêcheux sob a noção de discursividade.

6 Já que através das vozes gramaticais, muitas vezes o sujeito é colocado como complemento e não mais sujeito da ação.

7 Termo utilizado pelo psicanalista Jean Allouch, ao evidenciar em seu livro a direção do tratamento utilizada por Lacan no caso Aimée.

Apoio financeiro: FAPESP - bolsa de mestrado concedida para primeira autora; CNPq - bolsa de produtividade para o segundo autor.

Este artigo de revista Estudos e Pesquisas em Psicologia é licenciado sob uma Licença Creative Commons Atribuição-Não Comercial 3.0 Não Adaptada. 